\title{
Strong-Motion Generation Areas of a Great Subduction-Zone Earthquake: Waveform Inversion with Empirical Green's Functions for the 2003 Tokachi-oki Earthquake
}

\author{
by A. Nozu and K. Irikura
}

\begin{abstract}
A waveform inversion with empirical Green's functions was conducted to estimate strong-motion generation areas (SMGAs) of the 2003 Tokachi-oki, Japan, earthquake $\left(M_{\mathrm{w}} 8.3\right)$. Although the rupture process of this great subduction-zone earthquake has been revealed with waveform inversions based on low-frequency (lower than $0.2 \mathrm{~Hz}$ ) ground motions, it is much more important from an engineering point of view to investigate how strong ground motions with higher frequencies were generated from the earthquake. Waveform data with higher frequencies have been excluded from the conventional inversions because of the difficulty in computing realistic theoretical Green's functions at higher frequencies. In this study, with the aid of empirical Green's functions, we extended the applicability of the waveform inversion to higher-frequency ground motions up to $1 \mathrm{~Hz}$. We selected three aftershocks for use in the analysis, referring to the similarity of the group delay time between the mainshock and the aftershock records. The resultant slip model has three SMGAs, each of which is close to the hypocenter of one of the aftershocks used. Generally speaking, locations of the SMGAs identified in this study agree well with asperities identified from the inverted results using low-frequency (lower than $0.2 \mathrm{~Hz}$ ) ground motions plus geodetic data and tsunamis. It implies that strong ground motions up to $1 \mathrm{~Hz}$ were generated from almost the same asperities producing lower-frequency ground motions. In terms of the complexity of slip models, although our analysis is focused on high frequencies, our slip model is at least as simple as conventional lowfrequency slip models. Such results would be useful in constructing source models of future great subduction-zone earthquakes for strong-motion prediction.
\end{abstract}

\section{Introduction}

A great subduction-zone earthquake occurred on $26 \mathrm{Sep}-$ tember 2003 off the Tokachi Region, Hokkaido, Japan. According to the Japan Meteorological Agency (JMA) unified source catalog, the hypocentral parameters are origin time, 04:50:07.64 JST; epicenter, $41.780^{\circ} \mathrm{N}, 144.078^{\circ} \mathrm{E}$; depth, $42 \mathrm{~km}$; and magnitude $M_{\mathrm{J}} 8.0\left(M_{\mathrm{w}} 8.3\right)$. As reported by Hatayama et al. (2004) and Koketsu et al. (2005), the earthquake caused serious damage to oil storage tanks in Hokkaido, Japan. The earthquake provided a large number of strong-motion records, from which we can study how strong ground motions were generated from the great subductionzone earthquake. In this study, a waveform inversion with empirical Green's functions was conducted to estimate strong-motion generation areas (SMGAs) of the earthquake that generated high-frequency ground motions up to $1 \mathrm{~Hz}$.

The strong motions from the earthquake were observed in recently developed nationwide strong-motion networks in Japan including K-NET (Kinoshita, 1998) and KiK-net (Aoi et al., 2000). Strong-motion data from the earthquake are far superior to those from any past $M$ 8-class earthquakes in terms of both quality and quantity. The 1968 Tokachi-oki earthquake $\left(M_{\mathrm{J}} 7.9\right)$, the source region of which is different from that of the 2003 event, for example, was observed at approximately 15 strong-motion stations (e.g., Tsuchida et al., 1969). The 2003 Tokachi-oki earthquake, in contrast, was observed at more than $600 \mathrm{~K}-\mathrm{NET}$ and KiK-net stations (Honda et al., 2004). This amount of strong-motion data gave us a rare opportunity to investigate how strong ground motions were generated from a great subduction-zone earthquake.

Slip models for the earthquake have been proposed by several authors. Yamanaka and Kikuchi (2003) investigated the source process of the earthquake using teleseismic body waves. Yagi (2004) conducted a joint inversion of teleseismic body waves and strong ground motions. Honda et al. (2004) conducted a waveform inversion of strong-motion data. 
Koketsu et al. (2004) conducted a joint inversion of strongmotion and geodetic data. These studies suggest that the rupture mainly propagated in the down-dip direction, with major asperities away from the hypocenter.

Although these studies provided important constraints on the rupture process at low frequencies, these studies effectively do not cover ground motions with frequencies higher than $0.2 \mathrm{~Hz}$. Although Yamanaka and Kikuchi (2003) and Yagi (2004) used displacement waveforms with frequencies lower than 0.5 or $1 \mathrm{~Hz}$, their main focus is on frequencies lower than $0.2 \mathrm{~Hz}$ as can be seen from figure 3 of Yamanaka and Kikuchi (2003) or figure 8 of Yagi (2004). The restrictions on the frequency range in these studies arise from the difficulty in computing realistic theoretical Green's functions at higher frequencies due to insufficient knowledge on subsurface structures in and around the source region.

In this study, we try to estimate strong-motion generation areas that produced ground motions with frequencies from 0.1 to $1 \mathrm{~Hz}$. Ground motions in this frequency range are of engineering interest because of the following two reasons: First, many structures including tall buildings and long bridges have their natural frequencies in the same frequency range. Second, sedimentary basins in Japan, which underlie most of the major cities in Japan, tend to amplify ground motions in this frequency range. It is therefore quite important to investigate how ground motions up to $1 \mathrm{~Hz}$ are generated from a great subduction-zone earthquake. This kind of investigation will play a vital role in the effort to predict strong ground motions from future huge subduction earthquakes including the scenario Tokai, Tonankai, and Nankai earthquakes and to evaluate performance of structures subject to predicted ground motions.
Source processes for shallow crustal earthquakes have been successfully modeled in a deterministic approach from the waveform inversions using strong-motion data in the frequency range from 0.1 to $1 \mathrm{~Hz}$ (e.g., Miyakoshi et al., 2000). Our intention is to reconstruct a fault rupture process effective in the same frequency range for the earthquake occurring in a subduction zone. We, therefore, use aftershock records as empirical Green's functions (Hartzell, 1978; Irikura, 1983) instead of theoretical Green's functions. In the empirical Green's function method, it is necessary to use a small event that shares the path and the site effects with the large event. Because the source region is large for the 2003 Tokachi-oki earthquake, it is not appropriate to represent contributions from the entire rupture with only one small event. A large number of aftershocks following the 2003 Tokachi-oki earthquake were recorded by K-NET and KiK-net. We selected several aftershocks to be used simultaneously in the inversion. Kamae and Kawabe (2004) also applied the empirical Green's function method to the earthquake and developed a source model composed of three asperities with forward modeling using records from a single aftershock. We selected three aftershocks to be used in the analysis to represent the Green's functions from different parts of the mainshock rupture area more adequately.

In this study, we focus on the following two issues: The first purpose is to confirm that the ground motions in the frequency range up to $1 \mathrm{~Hz}$ from a great subduction-zone earthquake can be modeled in a deterministic manner, once realistic Green's functions become available. The second purpose is to compare the slip model obtained here with models so far obtained from ground-motion data at lower frequencies. It is very important to investigate whether or
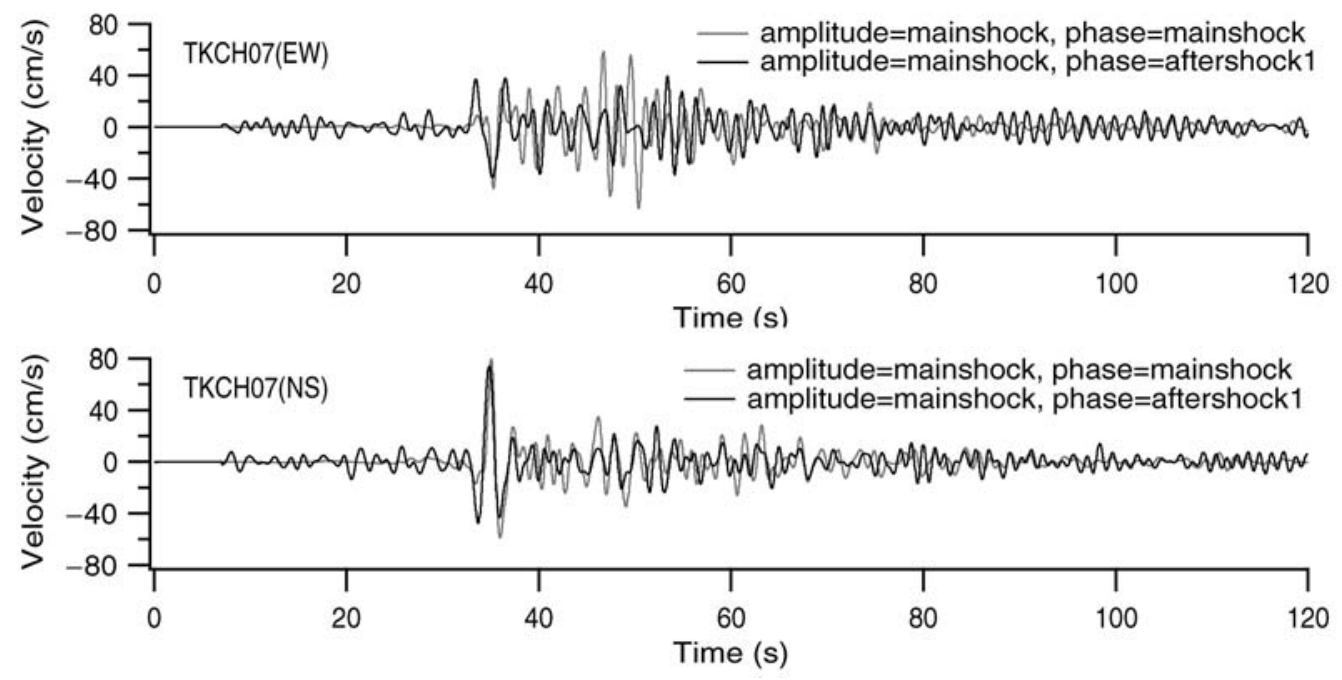

Figure 1. Observed velocity waveforms for the mainshock on the ground surface at TKCH07 (gray traces) and the calculated velocity waveforms for Fourier amplitude of the mainshock and Fourier phase of aftershock 1 (black traces). Both traces are band-pass filtered between 0.1 and $1.0 \mathrm{~Hz}$. The similarity of the traces indicates that the mainshock and aftershock 1 share the path and site effects for the site. 
not SMGAs coincide with asperities that produce lowerfrequency ground motions. Such an investigation is essential in constructing reliable source models of future great subduction-zone earthquakes for strong-motion prediction.

\section{Selection of Empirical Green's Functions}

In the empirical Green's function method, it is important to use appropriate Green's functions; that is, it is necessary to find a small event that shares the path and the site effects with the large event. From the large number of aftershocks that followed the 2003 Tokachi-oki earthquake, we selected appropriate aftershocks to be used in the analysis, referring to the similarity of the Fourier phase or the "group delay time" between the mainshock and the aftershock records as follows.

In Figure 1, the gray traces indicate the observed velocity waveforms for the mainshock on the ground surface at the KiK-net station TKCH07 (locations of the stations are shown in Fig. 2). On the other hand, the black traces indicate calculated velocity waveforms for the Fourier amplitude of the mainshock and the Fourier phase of aftershock 1 (source parameters for the aftershocks as well as the mainshock are listed in Table 1; epicenters of the aftershocks are shown in Fig. 2). Both traces are band-pass filtered between 0.1 and $1 \mathrm{~Hz}$. From Figure 1, we can recognize the similarity of the traces.

The two traces (gray and black) in Figure 1 have the same amplitude spectra as the mainshock but different phase spectra: one is the mainshock, and the other is aftershock 1. The group delay time (e.g., Sawada et al., 1998; Beauval et al., 2003) is defined as the derivative of the phase spectra with respect to angular frequency. The similarity of the two traces means coincidence of the group delay time between the mainshock and aftershock 1. In general, the group delay time of a ground motion is the sum of the source, path, and site effects as pointed out by Sawada et al. (1998) and Beauval et al. (2003). The source effect, however, is relatively small as can be seen in the following example. Let us consider a simple source time function of an asperity represented by a boxcar function with a duration of $2 b$ (Fig. 3 ). Then the Fourier transform of the function can be expressed as $(2 / \omega) \sin (\omega b)$, which is a real number. Thus, both the Fourier phase and the group delay time of the function are zero for all $\omega$. Thus, the source process of the mainshock asperity does

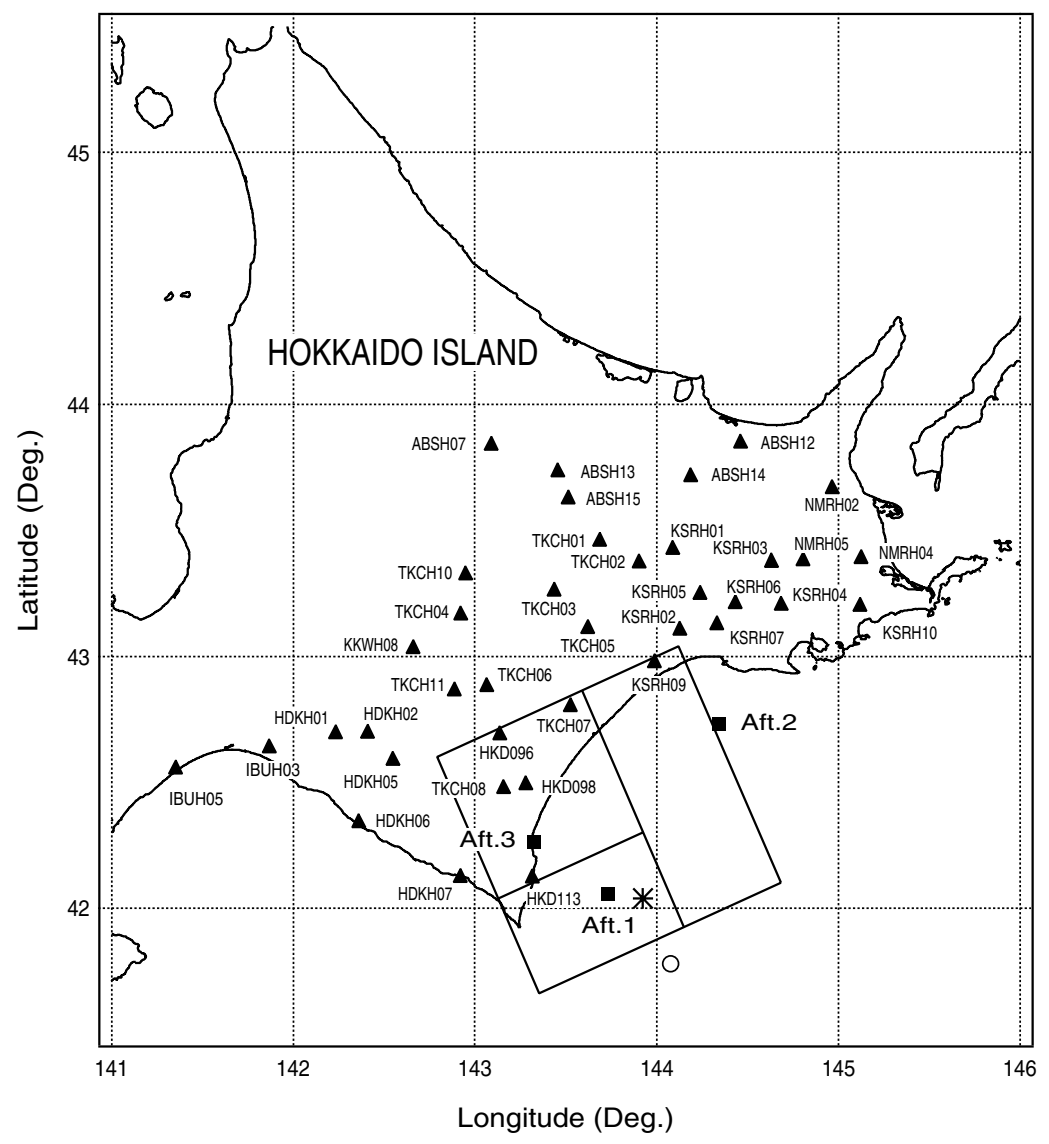

Figure 2. A map showing the JMA hypocenters of the mainshock (open circle) and the aftershocks (solid squares), the fault plane assumed for the inversion (large rectangle), the center of the rupture front assumed for the inversion (asterisk), and the K-NET and KiK-net stations used for the inversion (solid triangles). 
Table 1

Parameters for the Mainshock and Aftershocks

\begin{tabular}{|c|c|c|c|c|c|c|c|c|}
\hline & Date (mm/dd/yyyy) & Time ${ }^{*}$ JST & Latitude $^{*}$ (deg) & Longitude $^{*}$ (deg) & Depth $^{*}(\mathrm{~km})$ & $M_{\mathrm{J}}^{*}$ & $M_{0}(\mathrm{Nm})$ & (Strike, Dip, Rake) (deg) \\
\hline Mainshock & $09 / 26 / 2003$ & 4:50:07.64 & 41.780 & 144.078 & 42.0 & 8.0 & $8.21 \mathrm{E}+20^{\dagger}$ & $(249,15,127)^{\dagger}$ \\
\hline Aftershock 1 & $09 / 26 / 2003$ & $7: 20: 22.49$ & 42.057 & 143.734 & 40.9 & 5.2 & 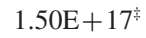 & $(216,64,87)^{\S}$ \\
\hline Aftershock 2 & $09 / 27 / 2003$ & $17: 06: 21.56$ & 42.733 & 144.346 & 59.2 & 5.2 & $1.02 \mathrm{E}+17^{\dagger}$ & $(233,26,111)^{\dagger}$ \\
\hline Aftershock 3 & $09 / 28 / 2003$ & $9: 23: 11.30$ & 42.265 & 143.324 & 43.4 & 5.0 & $3.95 \mathrm{E}+16^{\dagger}$ & $(239,20,112)^{\dagger}$ \\
\hline
\end{tabular}

*After JMA.

${ }^{\dagger}$ After F-net (available at www.fnet.bosai.go.jp).

Estimated from Fourier spectral ratios of aftershocks 1 and 2.

${ }^{\S}$ After Hi-net (available at www.hinet.bosai.go.jp).

not have significant effects on the group delay time of the observed ground motion, although its effects on the Fourier amplitude are significant. Thus, the similarity of the group delay time in Figure 1 suggests that the mainshock and aftershock 1 share the path and the site effects for the specific site. More strictly, aftershock 1 shares the path and the site effects with a part of the mainshock rupture that contributed most to the ground motions at TKCH07. The similarity of the group delay time between the mainshock and aftershock 1 can be seen at many other stations. Because of such characteristics, aftershock 1 is preferable as a small event to be used in the empirical Green's function method. Aftershock 1 was also used by Kamae and Kawabe (2004).

There are stations, however, where the mainshock group delay time is not similar to that of aftershock 1 . The KiK-net station KSRH09 (see Fig. 2), which is located east of TKCH07, is such an example (Fig. 4). At KSRH09, the group delay time of the north-south component of the mainshock is different from that of aftershock 1 . For this site, we found that aftershock 2 (see Table 1 and Fig. 2) gives more preferable results for both the east-west and the north-south components (Fig. 5). In addition, we found a general tendency that at stations in the Kushiro region, that is, the stations with abbreviations beginning with KSR (see Fig. 2), aftershock 2 gives more preferable results than aftershock 1 .

At several stations in the west, neither aftershock 1 nor aftershock 2 gives good results (Fig. 6), and after some trials we found that aftershock 3 (see Table 1 and Fig. 2) gives the

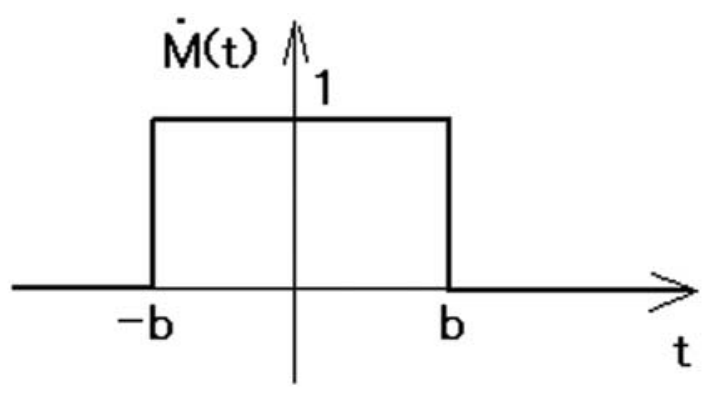

Figure 3. A simple source time function of an asperity used to evaluate the effects of its rupture on the group delay time. best results for those stations (Fig. 7). Based on such investigations, we decided to use aftershocks 1,2 , and 3 at the same time in the ensuing analysis as illustrated in the next section.

The same procedure to find appropriate aftershocks for use in the empirical Green's function method was also applied to the 2004 mid-Niigata Prefecture, Japan, earthquake and contributed to the modeling of the near-source ground velocities in the frequency range from 0.2 to $1 \mathrm{~Hz}$ (Nozu, 2005).

\section{Inversion Method}

The stations used for the analysis are shown in Figure 2. We mainly used the KiK-net borehole data (Aoi et al., 2000) so that we can avoid significant effects of soil nonlinearity during the mainshock. There were $39 \mathrm{KiK}$-net stations that recorded all aftershocks 1, 2, and 3 and the mainshock. Four of the 39 stations, namely, HDKH04, ABSH06, ABSH11, and SRCH09, were excluded from the analysis because some of the aftershock records did not show a satisfactory signalto-noise ratio. To improve azimuthal coverage in the nearsource region, we added 3 K-NET stations (Kinoshita, 1998), namely, HKD096, HKD098, and HKD113, where data were obtained at the ground surface. The effect of soil nonlinearity might be small, however, at these stations for the frequency range of concern $(0.1-1 \mathrm{~Hz})$ because the thicknesses of the layers there with shear-wave velocity less than $300 \mathrm{~m} / \mathrm{sec}$ are only 3,1 , and $1 \mathrm{~m}$, respectively. As a result, the 38 stations shown in Figure 2 were used for the inversion. The observed accelerograms for both the mainshock and the aftershocks were band-pass filtered between 0.1 and $1 \mathrm{~Hz}$ and integrated in the frequency domain to obtain velocity waveforms.

Radial components were used in the waveform inversion considering the intensity of the radiation coefficient against the diversity of the rake angle as follows. According to the waveform inversion by Honda et al. (2004), the rake angle on the mainshock fault plane is not necessarily uniform. In the empirical Green's function method, however, the ground motions are synthesized assuming the same rake angle for the mainshock and the aftershocks. If the radiation coefficient is 

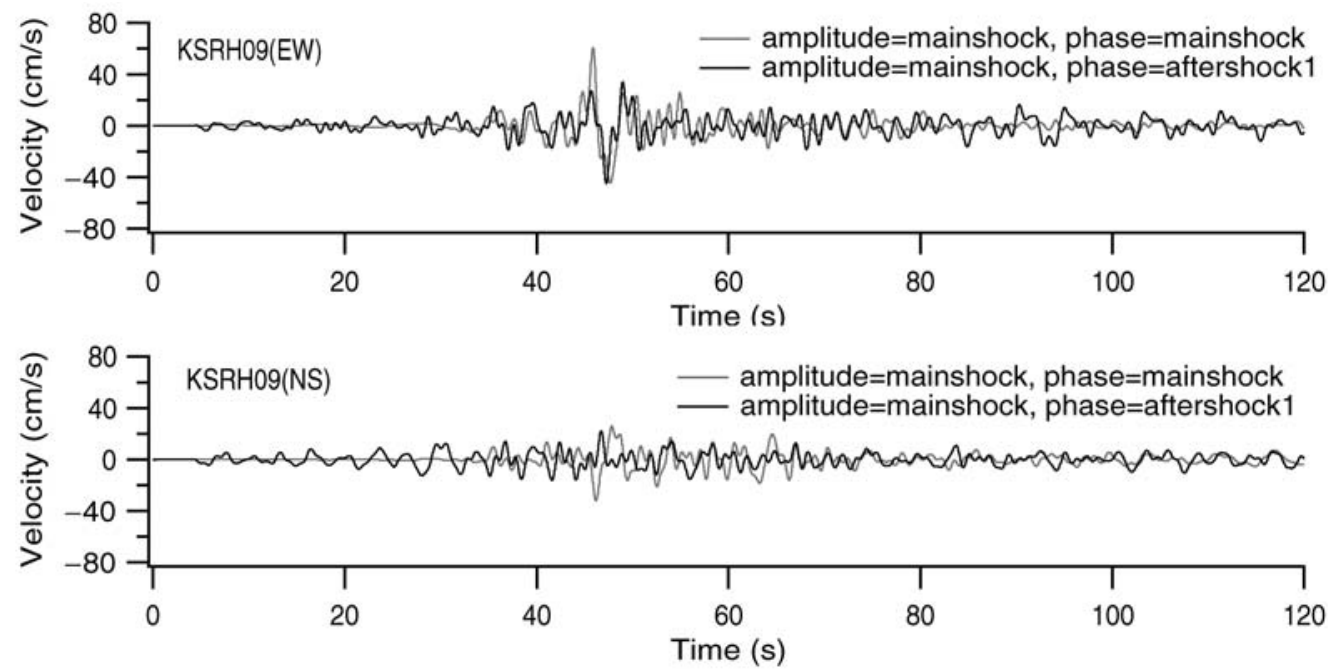

Figure 4. Observed velocity waveforms for the mainshock on the ground surface at KSRH09 (gray traces) and the calculated velocity waveforms for Fourier amplitude of the mainshock and Fourier phase of aftershock 1 (black traces). Both traces are band-pass filtered between 0.1 and $1.0 \mathrm{~Hz}$. The discrepancy of the traces indicates that the mainshock and aftershock 1 do not share the path and site effects for the site.

very sensitive to a small change in the rake angle, the waveform modeling with the empirical Green's functions might not be reasonable. We, therefore, investigated the sensitivity of the radiation coefficients for $S V$ and $S H$ waves to a small change in the rake angle for the mainshock. Figure 8 shows the sensitivity of the radiation coefficients for $S V$ and $S H$ waves to a small change in the rake angle defined as

$$
\Delta=\frac{\left|R_{110}-R_{90}\right|^{2}}{\left|R_{110}\right|\left|R_{90}\right|},
$$

where $R_{110}$ is the radiation coefficient for a point source at the JMA hypocenter with a rake angle of $110^{\circ}$ and $R_{90}$ is that with a rake angle of $90^{\circ}$. The strike and dip angles were set to be $246^{\circ}$ and $18^{\circ}$, respectively (Honda et al., 2004). The radiation coefficients were calculated by applying ray tracing assuming a layered subsurface structure used by Honda et al. (2004). The results indicate that the radiation coefficients for $S V$ waves are much less sensitive to a small change in the rake angle than those for $S H$ waves in the areas where strong-motion sites are located. Thus, we decided that radial components should be used in the waveform inversion. The
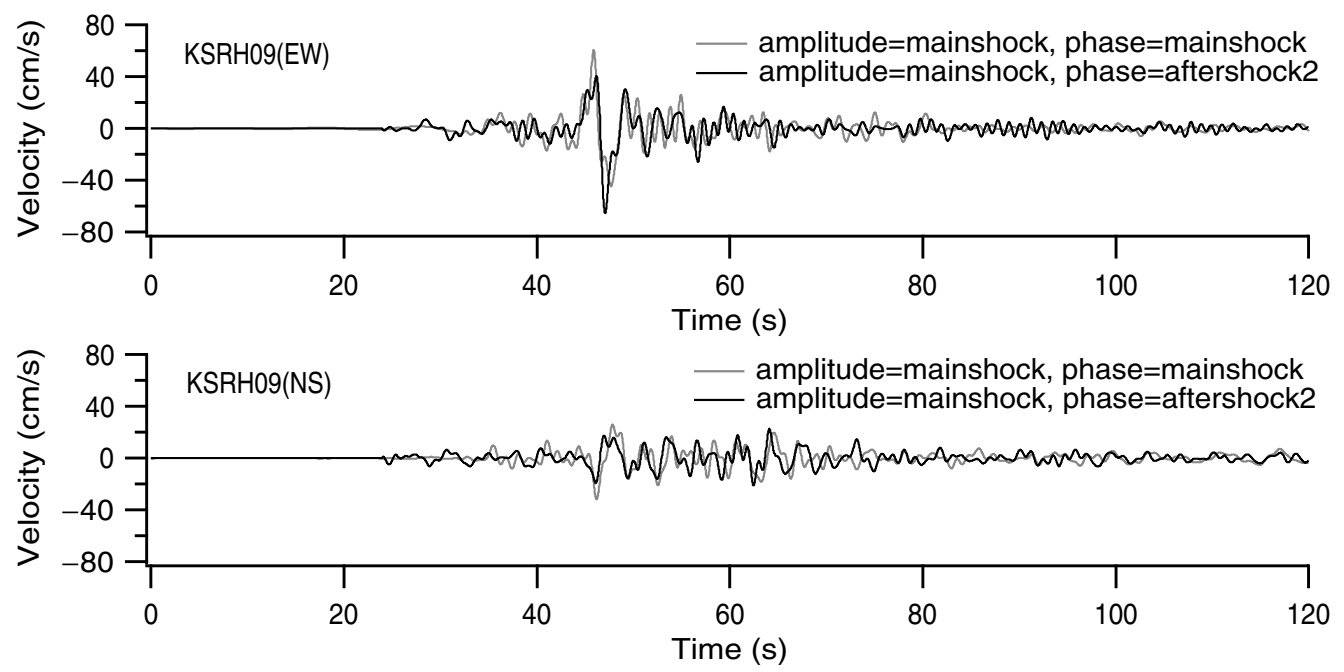

Figure 5. Observed velocity waveforms for the mainshock on the ground surface at KSRH09 (gray traces) and the calculated velocity waveforms for Fourier amplitude of the mainshock and Fourier phase of aftershock 2 (black traces). Both traces are band-pass filtered between 0.1 and $1.0 \mathrm{~Hz}$. The similarity of the traces indicates that the mainshock and aftershock 2 share the path and site effects for the site. 

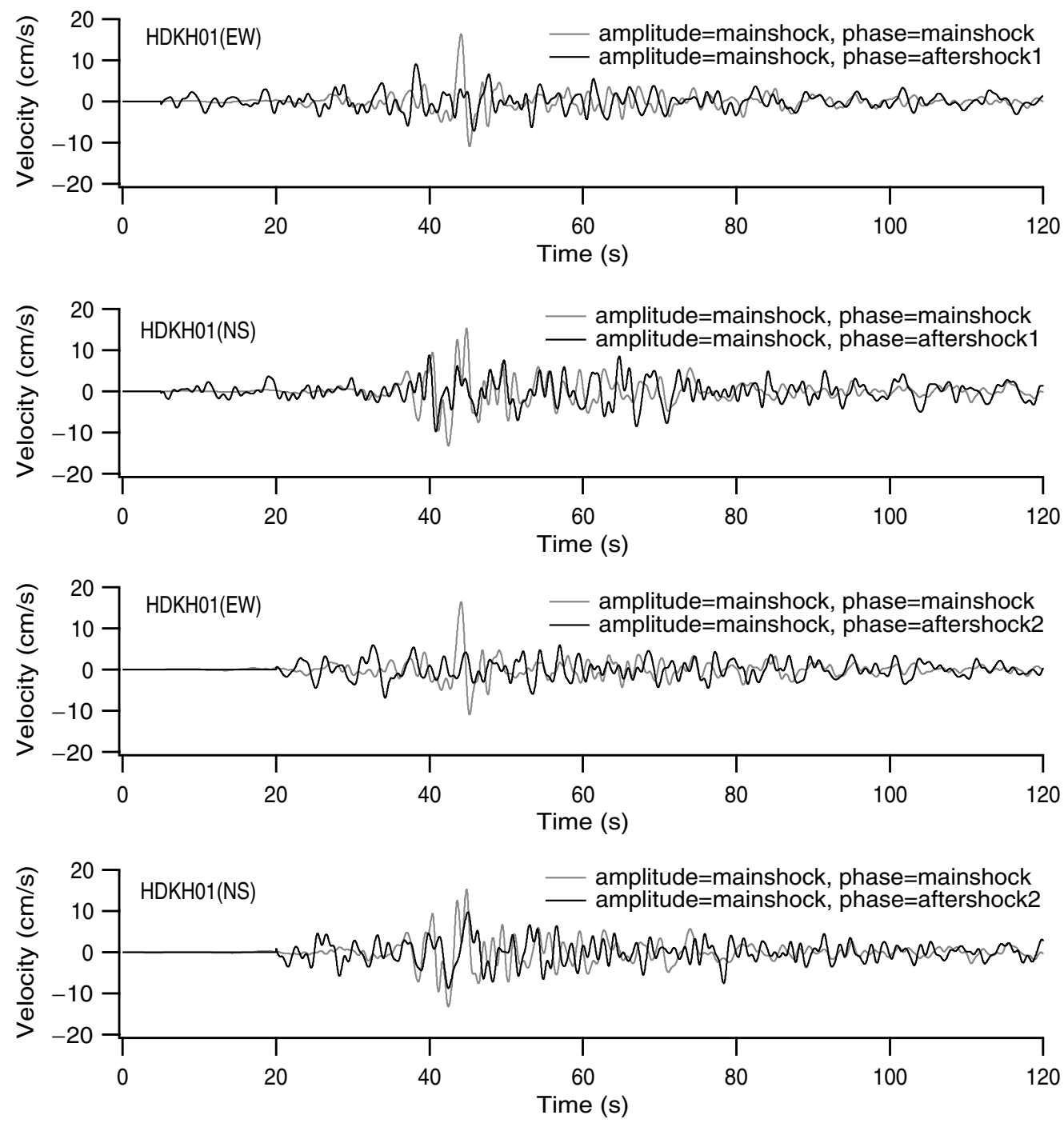

Figure 6. Observed velocity waveforms for the mainshock on the ground surface at HDKH01 (gray traces) and the calculated velocity waveforms for Fourier amplitude of the mainshock and Fourier phase of aftershock 1 (upper two black traces) or aftershock 2 (lower two black traces). Both traces are band-pass filtered between 0.1 and $1.0 \mathrm{~Hz}$. The discrepancy of the traces indicates that neither aftershock 1 nor aftershock 2 shares the path and site effects with the mainshock for the site.

application of the present slip model to the transverse components will be discussed later.

The conventional least-squares linear waveform inversion (Hartzell and Heaton, 1983) was adopted. A fault plane with a dimension of 120 by $120 \mathrm{~km}$ was assumed (Fig. 2), whose strike and dip angles were set to be $246^{\circ}$ and $18^{\circ}$, respectively, to be consistent with the upper boundary of the subducting Pacific plate (Honda et al., 2004). The fault plane, that is, the rupture area, was divided into 30 by 30 elements. The rupture starting point is taken at a point (the asterisk in Fig. $2 ; 42.039^{\circ} \mathrm{N}, 143.925^{\circ} \mathrm{E}, 30-\mathrm{km}$ depth) that is approximately $30-\mathrm{km}$ northwest of the JMA hypocenter. We did not use the JMA hypocenter as the rupture starting point because, as long as we use the JMA hypocenter, we could not get good results. This is probably because the rupture front is assumed to propagate radially from the effective rupture starting point in our analysis. The rupture is assumed to start $4 \mathrm{sec}$ later than the JMA hypocentral time and to propagate radially at a constant velocity of $2.6 \mathrm{~km} / \mathrm{sec}$. This value of rupture velocity was selected based on the goodness of fit. The relation between the rupture velocity and the goodness of fit will be discussed later. Each fault element is allowed to slip 12 times in $6 \mathrm{sec}$ after passage of the rupture front at 0.5 -sec time intervals. The moment release of each slip relative to the moment of the selected aftershock was determined through the inversion.

In terms of aftershocks, three cases of the inversions are conducted (Fig. 9). In case 1, the contribution from the entire rupture area is computed using records from aftershock 1 . In case 2, the contribution from the western part of the fault is computed using records from aftershock 1 , while that from the eastern part of the rupture area is computed using records 

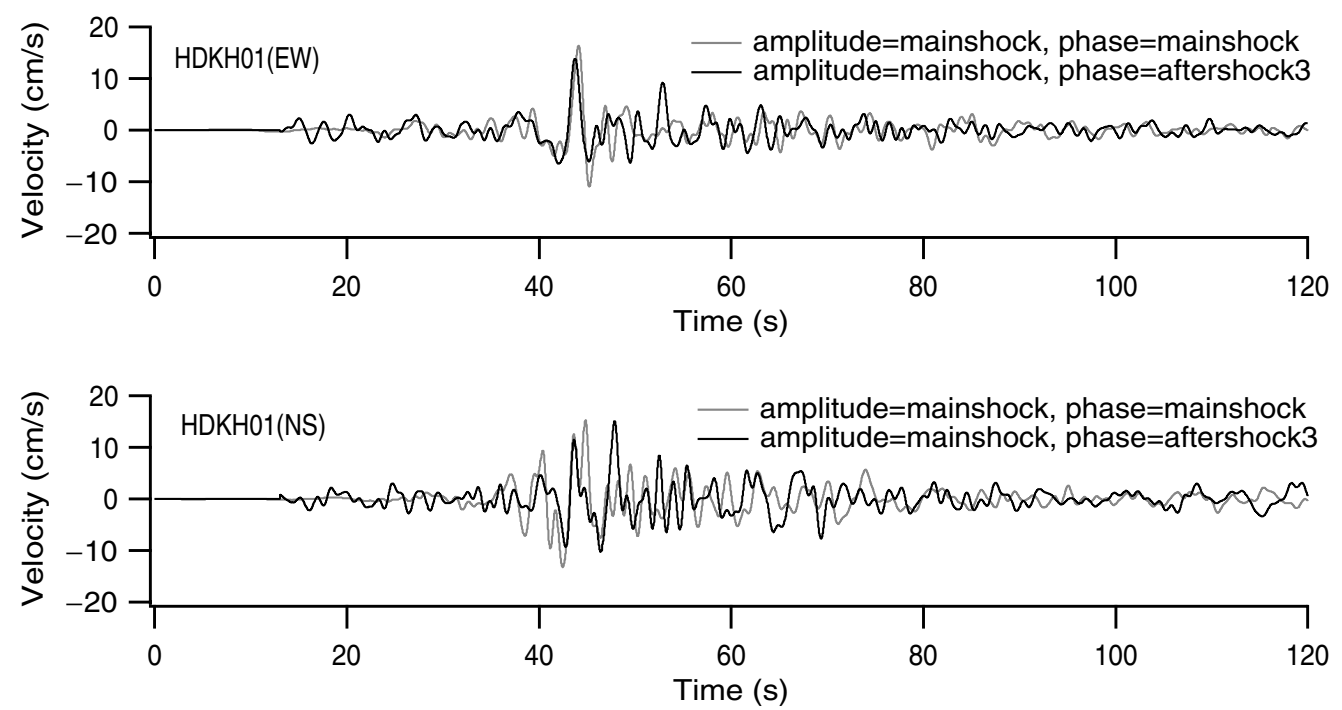

Figure 7. Observed velocity waveforms for the mainshock on the ground surface at HDKH01 (gray traces) and the calculated velocity waveforms for Fourier amplitude of the mainshock and Fourier phase of aftershock 3 (black traces). Both traces are band-pass filtered between 0.1 and $1.0 \mathrm{~Hz}$. The similarity of the traces indicates that the mainshock and aftershock 3 share the path and site effects for the site.
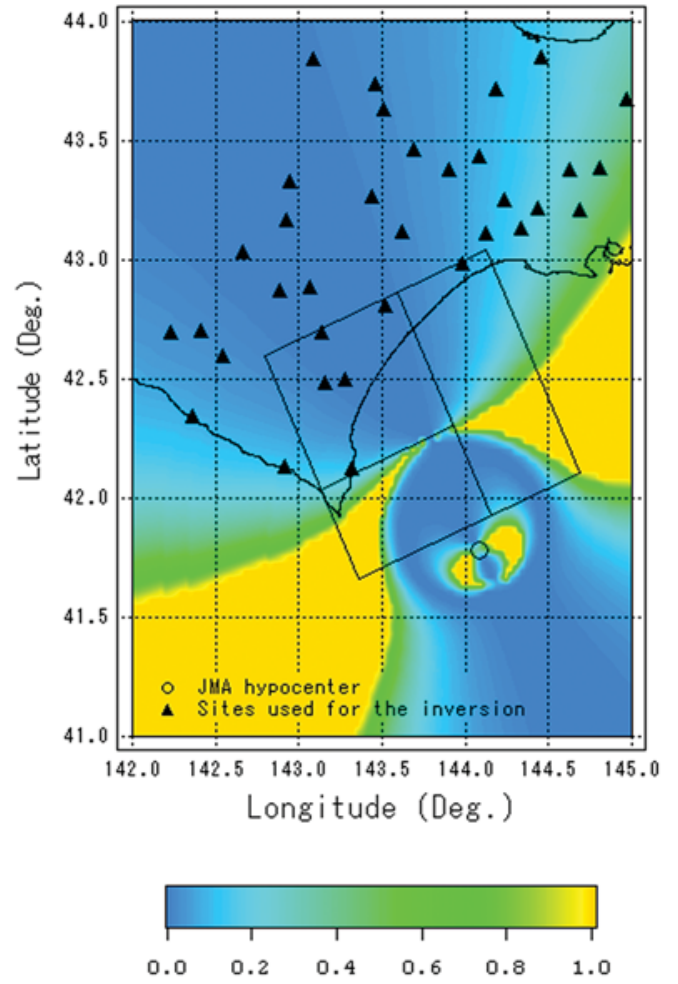

Sensitivity of SV radiation coeffecient
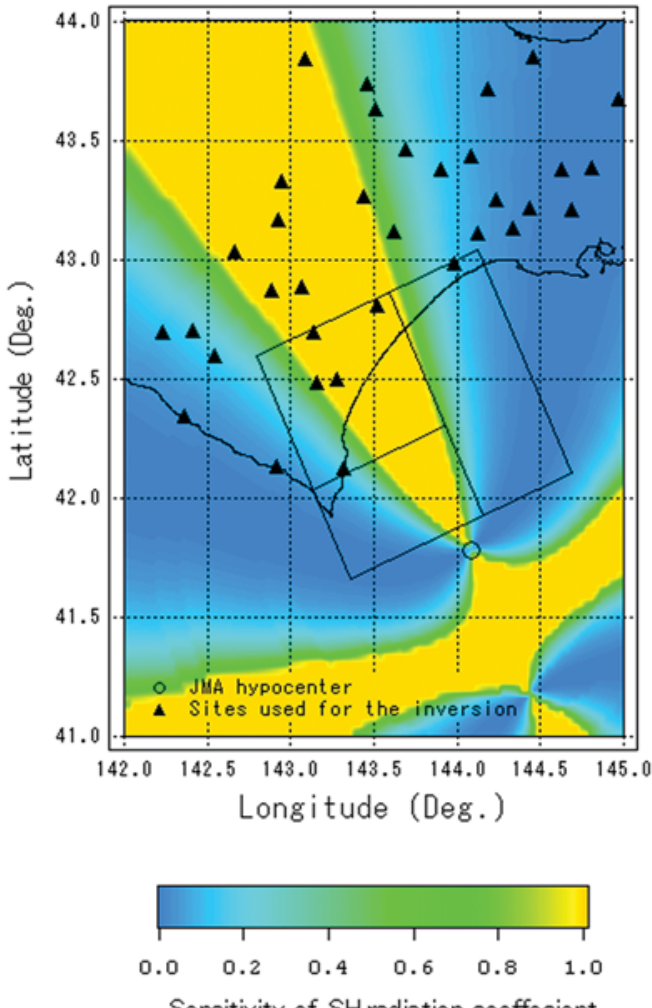

Sensitivity of $\mathrm{SH}$ radiation coeffecient

Figure 8. Sensitivity of radiation coefficients for $S V$ (left-hand panel) and $S H$ (right-hand panel) waves to a small change in the rake angle as defined in equation (1). If the sensitivity is larger than one, than it is set to be one in the figure. The radiation coefficients for $S V$ waves are much less sensitive to a small change in the rake angle than those for $S H$ waves in the areas where strong-motion sites are located. 


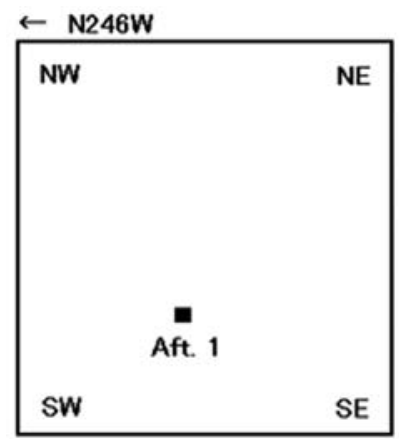

CASE 1

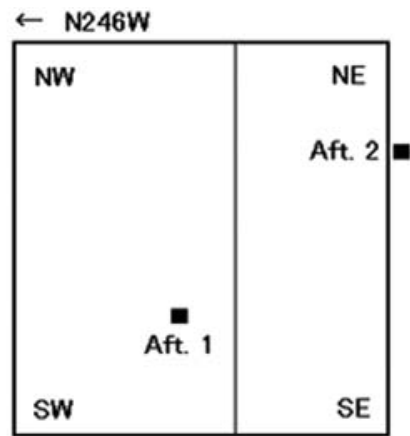

CASE 2

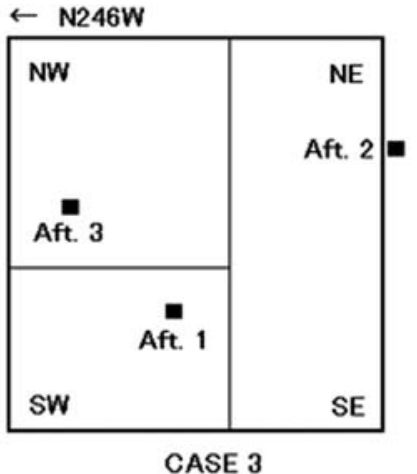

Figure 9. Three cases of inversions. In case 1, the contribution from the entire fault is computed using records from aftershock 1. In case 2, the contribution from the western part of the fault is computed using records from aftershock 1, while that from the eastern part of the fault is computed using records from aftershock 2. In case 3, the contribution from the southwestern part of the fault is computed using records from aftershock 1 , the contribution from the eastern part of the fault is computed using records from aftershock 2 , and the contribution from the northwestern part of the fault is computed using records from aftershock 3.

from aftershock 2 . In case 3 , the contribution from the southwestern part of the rupture area is computed using records from aftershock 1 , that from the eastern part of the rupture area is computed using records from aftershock 2 , and that from the northwestern part of the rupture area is computed using records from aftershock 3 .

Conventional corrections for the geometrical spreading and time shifts (Irikura, 1983) were applied to the empirical Green's functions to represent arrivals from each fault element. The aftershock locations determined by the JMA were used (Table 1) in conjunction with the shear-wave velocity in the source region of $3.8 \mathrm{~km} / \mathrm{sec}$ (Ide and Takeo, 1996). Ab- solute time information for both the mainshock and the aftershock records was used.

Nonnegative least-square solutions were obtained using the algorithm of Lawson and Hanson (1974). In the analysis, constraints were imposed to minimize the second order derivative of the slip on the rupture area. At boundaries of regions allotted to different aftershocks, the absolute moment from each element is assumed to be continuous, that is, the relative moment with respect to the aftershock is not necessarily continuous at the boundaries. The moments of aftershocks 2 and 3 are determined by the F-net (Fukuyama et al, 1996) as listed in Table 1. The moment of aftershock
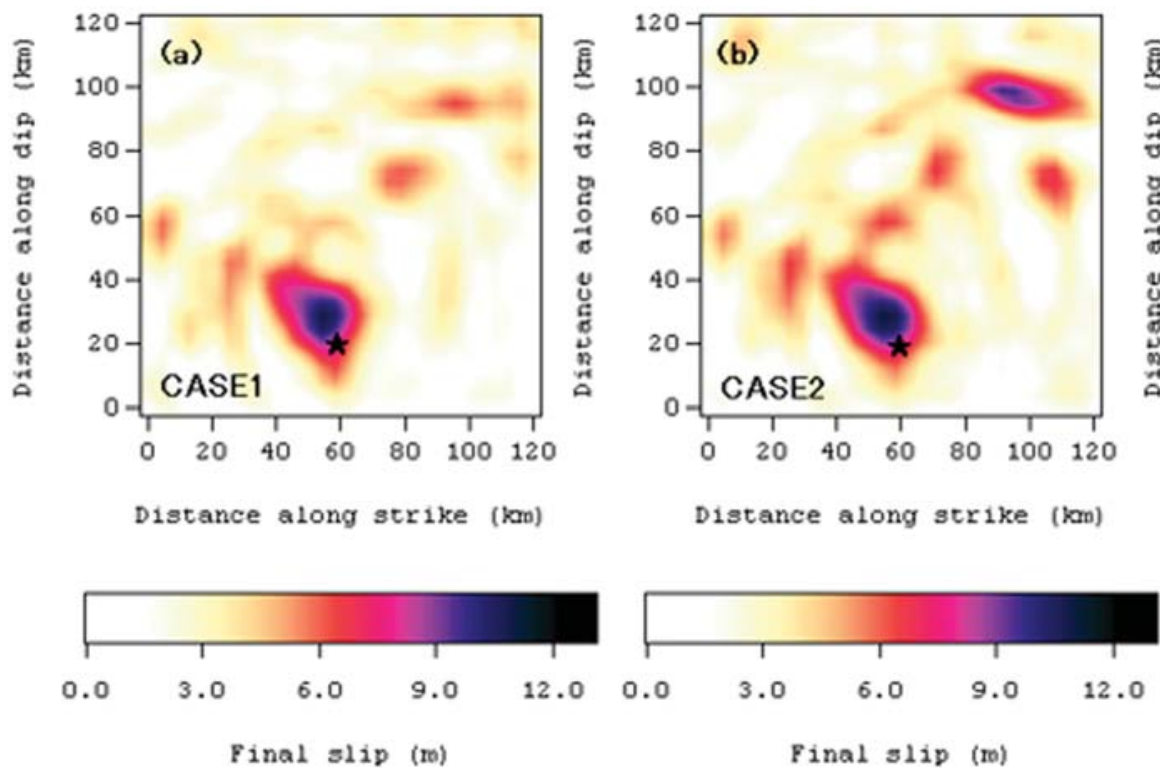

Figure 10. Slip models for the 2003 Tokachi-oki, Japan, earthquake obtained from three cases of waveform inversion. (a) The model obtained from case 1 using only one aftershock; (b) the model obtained from case 2 using two aftershocks; and (c) the model obtained from case 3 using three aftershocks, which is the final inversion. The star indicates the rupture starting point. 
1 was estimated from the averaged spectral ratio of aftershocks 1 and 2 at low frequencies at K-NET stations. In Table 1, the mechanisms of the centroid moment tensor solutions by the F-net for aftershocks 2 and 3 are listed. For aftershock 1, the mechanism estimated from the polarity distribution of the $P$ wave by the Hi-net (Obara, 2002) is shown.

\section{Results}

Inversion with One Aftershock

Figure 10a shows the slip model obtained from the inversion case 1 using only one aftershock. The inversion determines the distribution of the moment release in the rupture area relative to the aftershock moment. Then, using the aftershock moment listed in Table 1, absolute slip distribution in the rupture area is estimated as shown in Figure 10a, which is converted from the moment release distribution assuming a shear-wave velocity of $3.8 \mathrm{~km} / \mathrm{sec}$ and a density of $3.0 \mathrm{~g} / \mathrm{cm}^{3}$ (Ide and Takeo, 1996). The obtained slip model is quite simple. It has just one SMGA located close to the epicenter of aftershock 1 . The synthetic velocities $(0.1-1 \mathrm{~Hz})$ obtained from the model agree well with the observed one at more than a few stations including TKCH07 (Fig. 11). At some stations including KSRH03, however, the agreement is not satisfactory (Fig. 11). We, therefore, try to improve the result by including the second aftershock in the analysis.

\section{Inversion with Two Aftershocks}

Figure 10b shows the slip model obtained from the inversion case 2 using two aftershocks. The obtained slip model has two SMGAs. One is close to the epicenter of aftershock 1, which was also seen in the previous slip model, and the other is located close to the northeastern corner of the rupture area, closer to the epicenter of aftershock 2 . The synthetic velocities $(0.1-1 \mathrm{~Hz})$ obtained from the model at three stations are compared with the observed ones in Figure 12. The agreement between the synthetic and the observed velocities is again satisfactory for TKCH07. In addition, at KSRH03, the agreement has been much improved.

The fitting between the synthetic and the observed velocities is evaluated by a residual, defined as

$$
\mathrm{ERR}=\sqrt{\frac{1}{N_{\text {site }}} \sum_{i=1}^{N_{\text {site }}} \frac{\int_{t 1}^{t 2}\left[S_{i}(t)-O_{i}(t)\right]^{2} d t}{\int_{t 1}^{t 2}\left[O_{i}(t)\right]^{2} d t}},
$$

where $S_{i}(t)$ is the synthetic velocity at the $i$ th site, $O_{i}(t)$ is the observed velocity at the $i$ th site, $N_{\text {site }}$ is the number of sites used for the inversion and $\left(t_{1}, t_{2}\right)$ is the time section used for the inversion. As a result, the residual is $10 \%$ smaller for case 2 than for case 1 (Table 2).

At some stations in the west including HDKH01 (see Fig. 2), however, the agreement is not satisfactory (Fig. 12). We, therefore, try to further improve the result by including the third aftershock in the analysis.
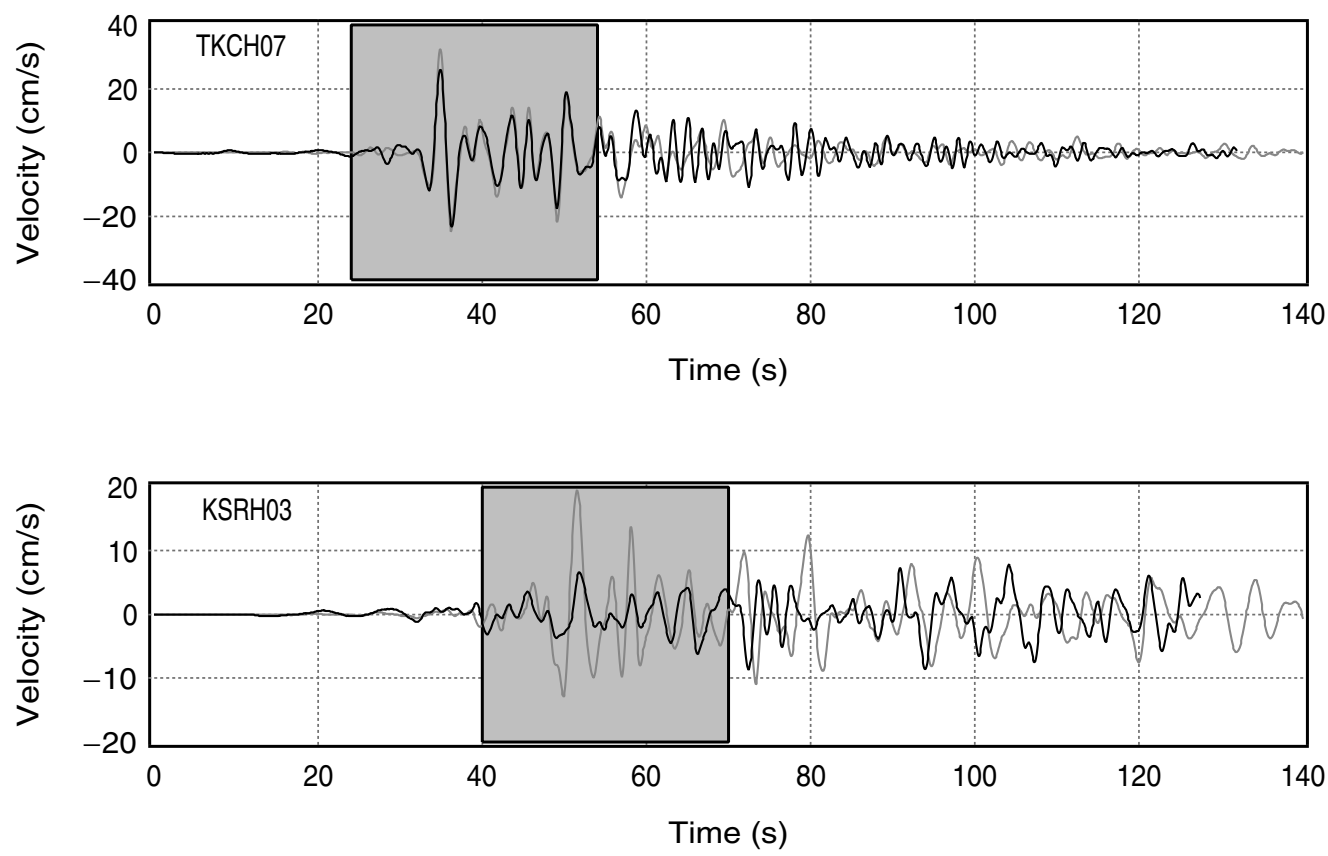

Figure 11. Comparison of the synthetic radial velocities $(0.1-1 \mathrm{~Hz})$ from the inversion case 1 (black traces) and the observed velocities (gray traces) at TKCH07 and KSRH03. Hatched portions are used for the inversion. 

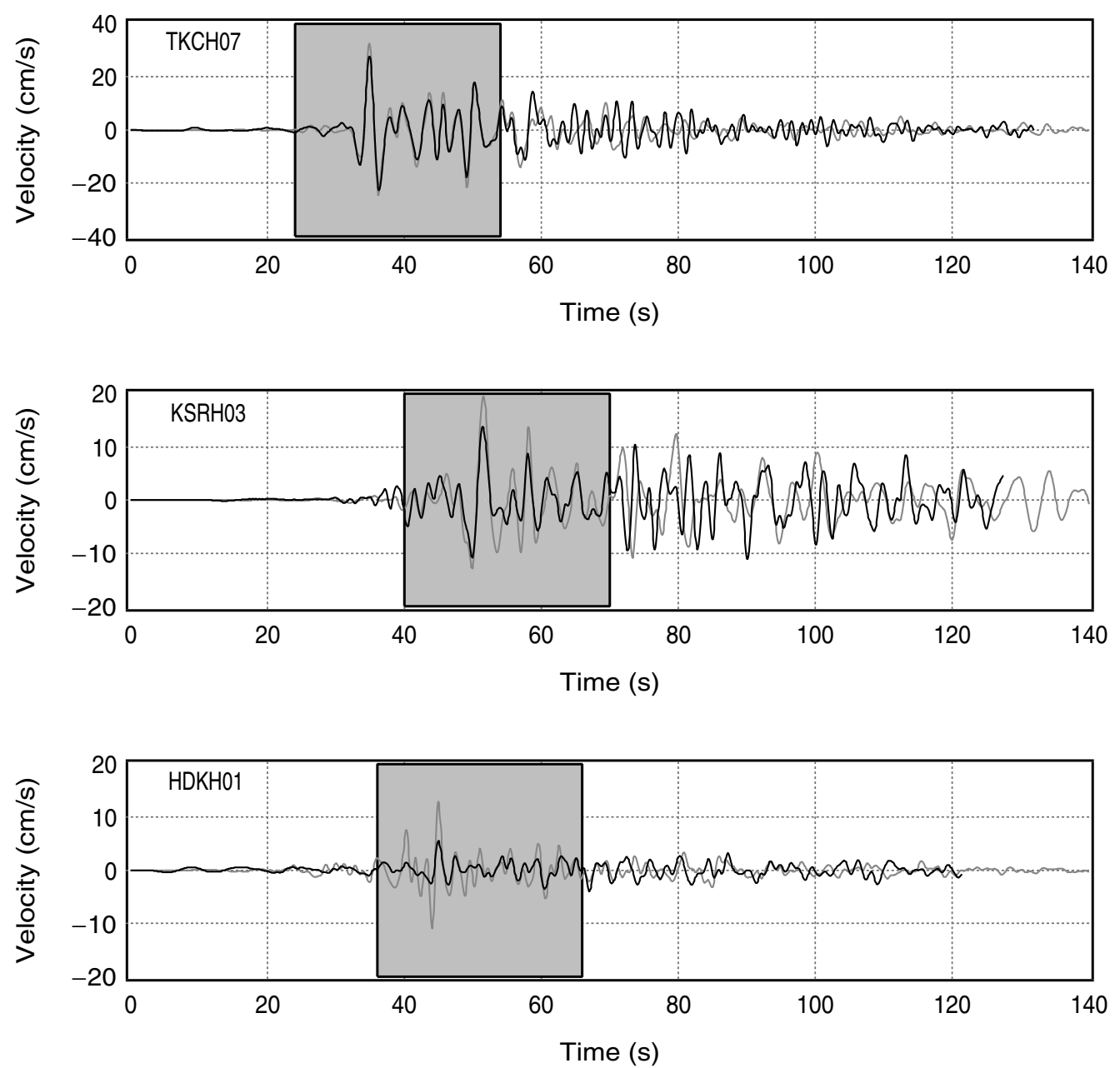

Figure 12. Comparison of the synthetic radial velocities $(0.1-1 \mathrm{~Hz})$ from the inversion case 2 (black traces) and the observed velocies (gray traces) at TKCH07, KSRH03, and HDKH01. Hatched portions are used for the inversion.

Inversion with Three Aftershocks

Figures 10c and 13 show the slip model obtained from the final inversion (case 3) using three aftershocks. The obtained slip model has three SMGAs. The first one is close to the hypocenter of aftershock 1 , the second one is close to that of aftershock 2, and the third one is close to that of aftershock 3 (Fig. 13). These SMGAs are hereafter referred to as SMGA 1, SMGA 2, and SMGA 3. The total moment of the model is $2.06 \mathrm{E}+21 \mathrm{Nm}\left(M_{\mathrm{w}} 8.1\right)$, which includes contributions from the SMGAs and the background area. The synthetic velocities $(0.1-1 \mathrm{~Hz})$ obtained from the model at all stations are compared with the observed ones in Figure 14. The agreement is satisfactory at almost all the stations including TKCH07, KSRH03, and HDKH01. The residual defined by equation (2) is $20 \%$ smaller for case 3 than for case 1 (Table 2). Thus, we prefer the slip model from case 3 . The goodness of fit is mainly due to the use of empirical Green's functions, which allows us to represent complicated path and site effects in the frequency range from 0.1 to $1 \mathrm{~Hz}$.
The reason why case 1 and case 2 cannot estimate some of the asperities can be explained as follows. Because the source region of the 2003 Tokachi-oki earthquake is so large, it is not appropriate to represent contributions from the entire rupture area with only one aftershock. For example, recordings from aftershock 1 are only appropriate for representing arrivals from the southwestern part of the fault; they do not share the path and the site effects with arrivals from other parts of the fault. Thus, as long as we use records from only aftershock 1, we cannot achieve good fits for parts of the

Table 2

ERR Values Defined in Equation (2) for Three Inversion Cases

\begin{tabular}{cc}
\hline Case & ERR \\
\hline 1 & 0.617 \\
2 & 0.555 \\
3 & 0.491 \\
\hline
\end{tabular}




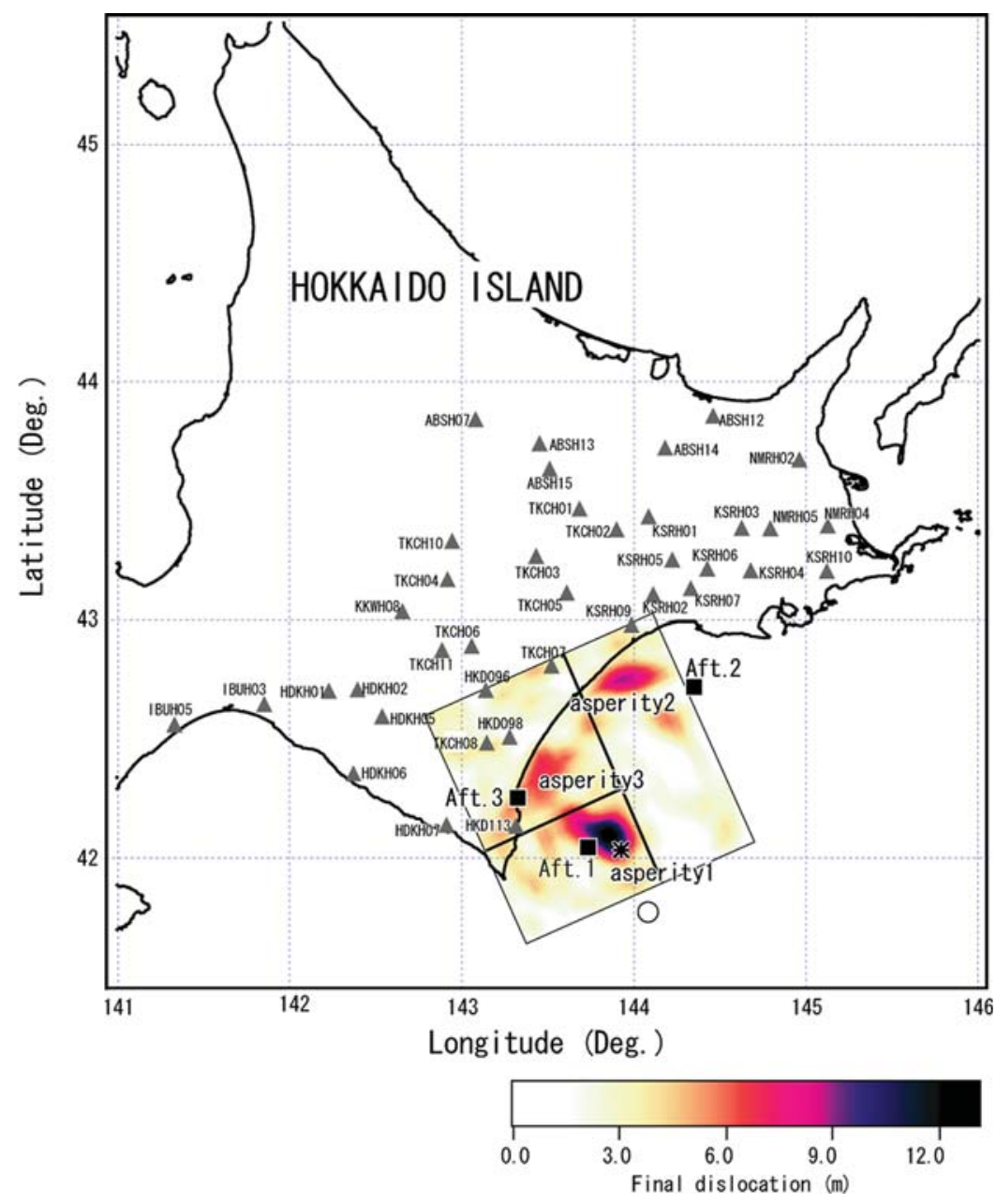

Figure 13. Slip model for the 2003 Tokachi-oki, Japan, earthquake obtained from the final inversion (case 3) using three aftershocks.

mainshock records that are affected by SMGA 2 or SMGA 3. This is why case 1 cannot estimate SMGA 2 and SMGA 3 and case 2 cannot estimate SMGA 3.

Figure 15 shows the slip for each time window of $4 \mathrm{sec}$ during the 2003 Tokachi-oki earthquake obtained by the final inversion. It can be observed that the rupture of SMGA 1 took place from 4 to $12 \mathrm{sec}$, while the rupture of SMGA 2 took place from 32 to $40 \mathrm{sec}$. The rupture of SMGA 3 took place from 20 to $28 \mathrm{sec}$, although the slip velocity is rather small compared to SMGA 1 and SMGA 2. Figure 16 shows representative slip velocity time functions for each SMGA. The time functions correspond to the element with the largest final slip in each SMGA. The slip velocity should be regarded as the averaged value over each time window used for the waveform inversion $(0.5 \mathrm{sec})$. In SMGA 1, where the largest slip occurred, the peak slip velocity averaged over the time window of $0.5 \mathrm{sec}$ is estimated to be at least as high as $3 \mathrm{~m} / \mathrm{sec}$.

Figure 17 shows the relation between the rupture velocity and ERR in equation (2). Based on the relation, we preferred the value of $2.6 \mathrm{~km} / \mathrm{sec}$ as the rupture velocity.

\section{Discussion}

Locations of SMGAs and Selected Aftershocks

In the preceding analysis, we selected three aftershocks for use in the analysis, referring to the similarity of the group delay time between the mainshock and the aftershock records. The inversion result indicates that the mainshock is composed of three SMGAs, each of which is close to the location of one of the aftershocks (Fig. 13). From this configuration of the SMGAs and the selected aftershocks, we can explain the reason for the similarity of the group delay time between the mainshock and the aftershock records (Figs. 1, 5 , and 7) as follows:

1. Ground motions at a site from the mainshock are roughly expressed as a sum of contributions from the three SMGAs. Some sites are affected dominantly by one of the three SMGAs and less by the other two, mostly depending on distance between the site and the SMGA.

2. Then, the observed records of an aftershock close to the SMGA are appropriate for the empirical Green's functions, because the path and site effects are shared between 

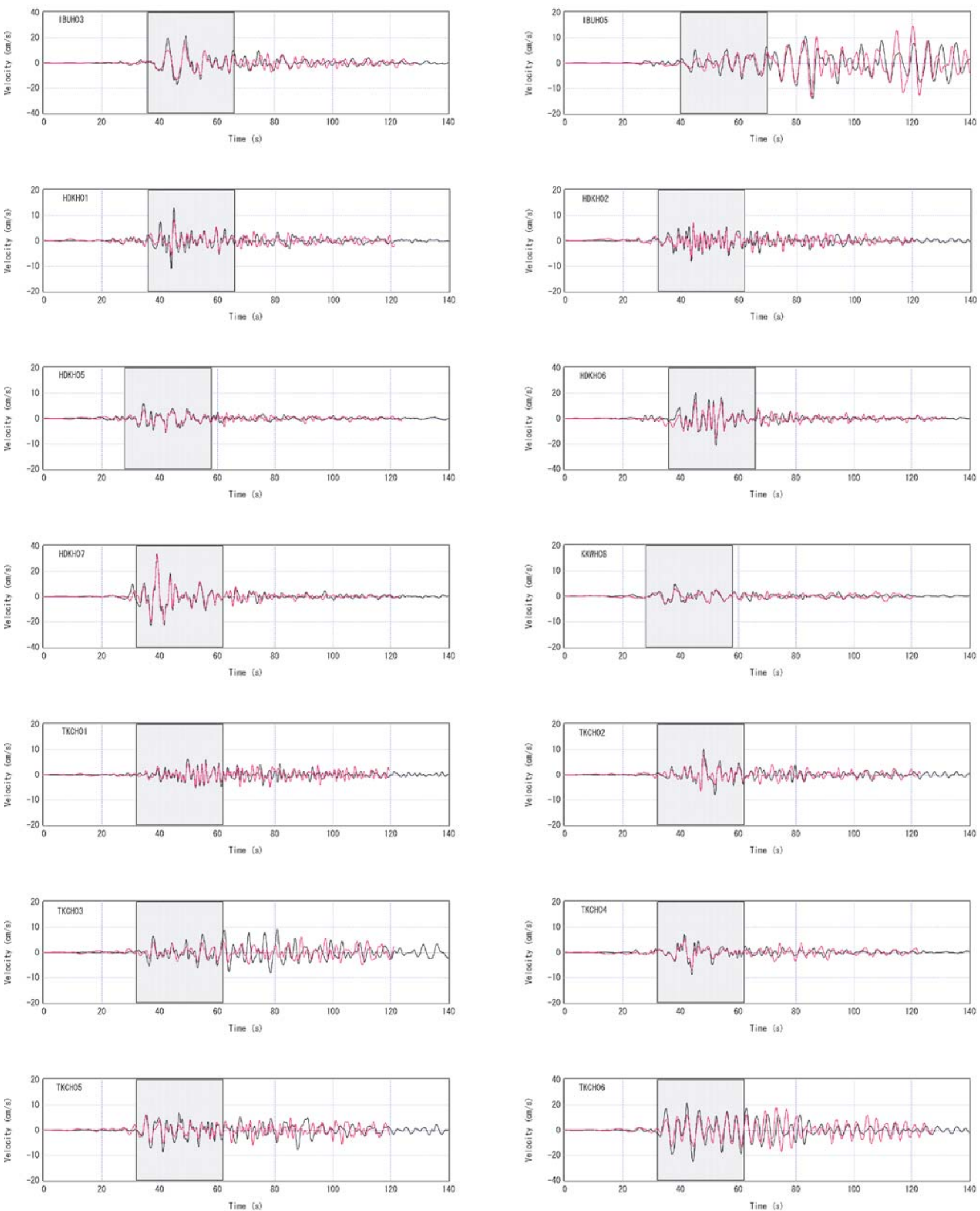

Figure 14. Comparison of the synthetic radial velocities $(0.1-1 \mathrm{~Hz})$ from the final inversion (case 3 ) (red traces) and the observed velocities (black traces) at all stations used for the inversion. The stations are aligned largely from west to east. Hatched portions are used for the inversion.

(Continued) 

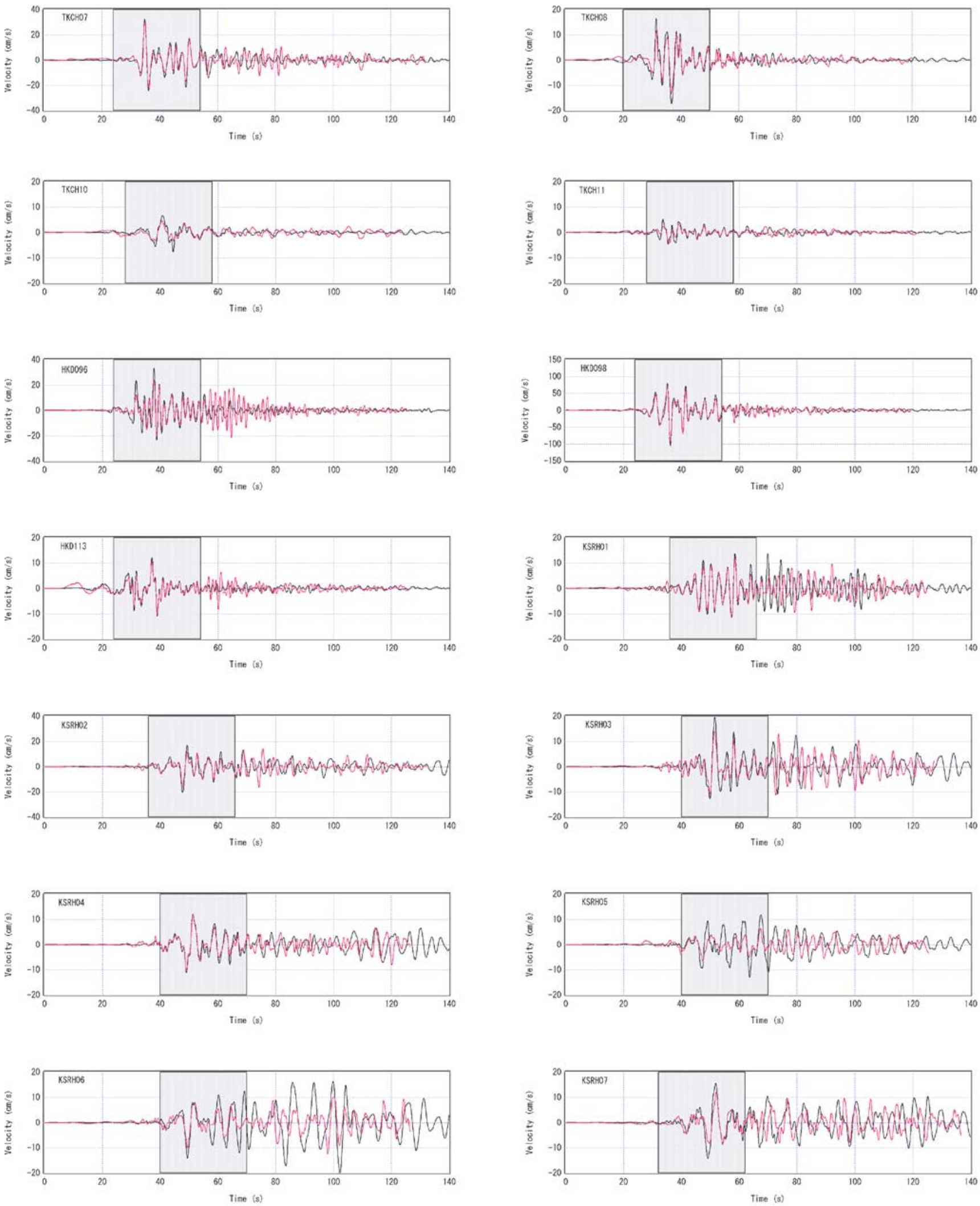

Figure 14. Continued. 

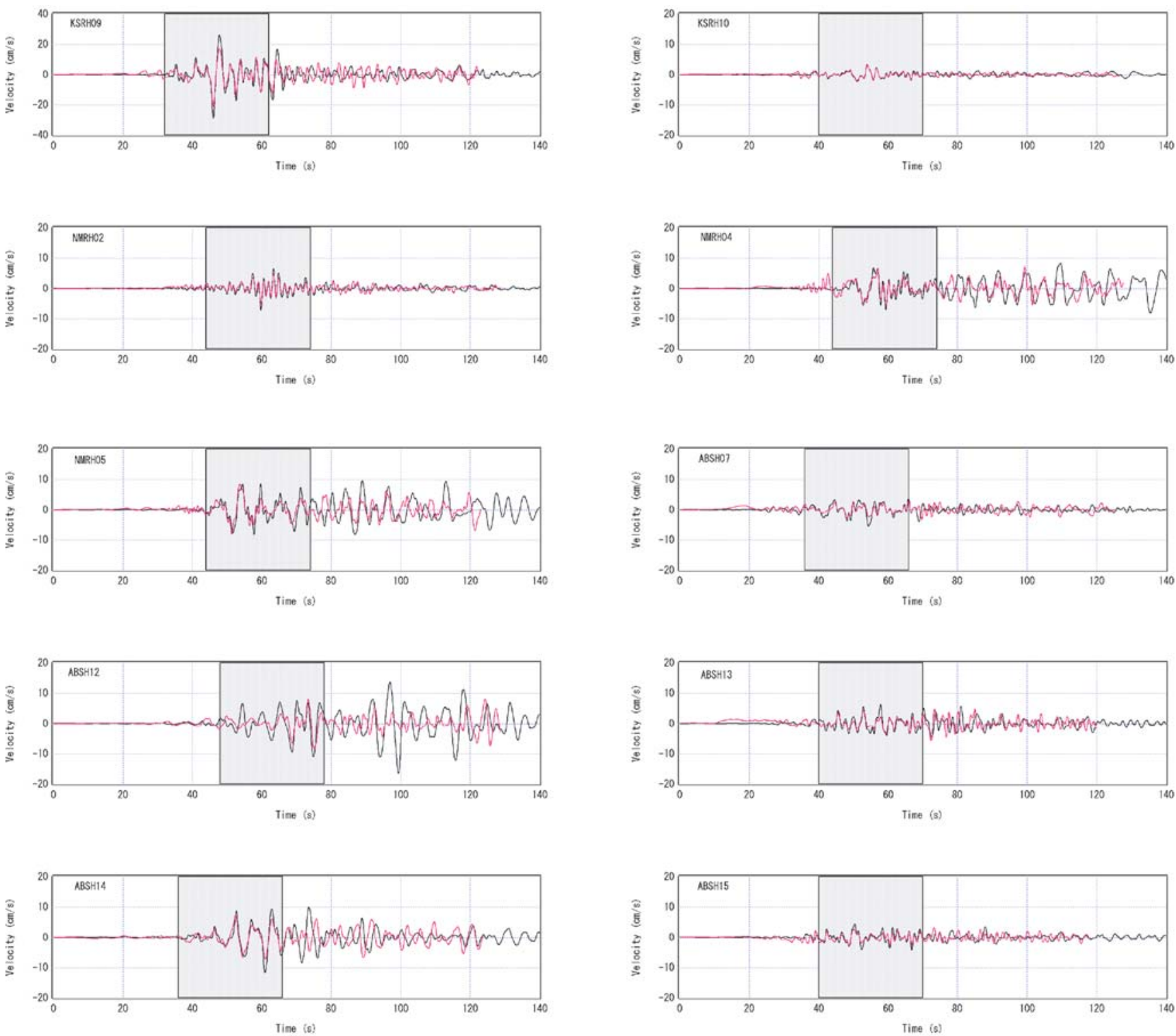

Figure 14. Continued.

the mainshock and the aftershock, resulting in a similarity of the group delay time between the mainshock and the aftershock for the specific site.

\section{Comparison with Low-Frequency Slip Models So Far Obtained}

As mentioned before, it is very important to investigate whether or not strong ground motions from a great subduction-zone earthquake are generated from the asperities defined as large slip areas from the waveform inversion of lower-frequency ground motions. Generally speaking, locations of the SMGAs identified in this study agree well with the asperities identified from lower-frequency ground motions in the previous studies.
The location of SMGA 1 in this study (Fig. 13) is almost the same as the location of the major asperity identified from the joint inversion of strong-motion and geodetic data by Koketsu et al. (2004). It is also almost the same as the region of major uplift identified from first-peak tsunami travel times (Hirata et al, 2004; region A of their fig. 3). The major asperity by Yamanaka and Kikuchi (2003), the asperity B by Yagi (2004) and the southern half of the asperity (b) by Honda et al. (2004) are close to our SMGA 1. SMGA 2 in this study (Fig. 13) is close to the asperity (c) by Honda et al. (2004). Areas of relatively large slip can also be found in the models of Yamanaka and Kikuchi (2003), Yagi (2004), and Koketsu et al. (2004), close to our SMGA 2, although they are not referred to as asperities in those studies. SMGA 3 in this study (Fig. 13) is close to the asperity $\mathrm{C}$ by Yagi 

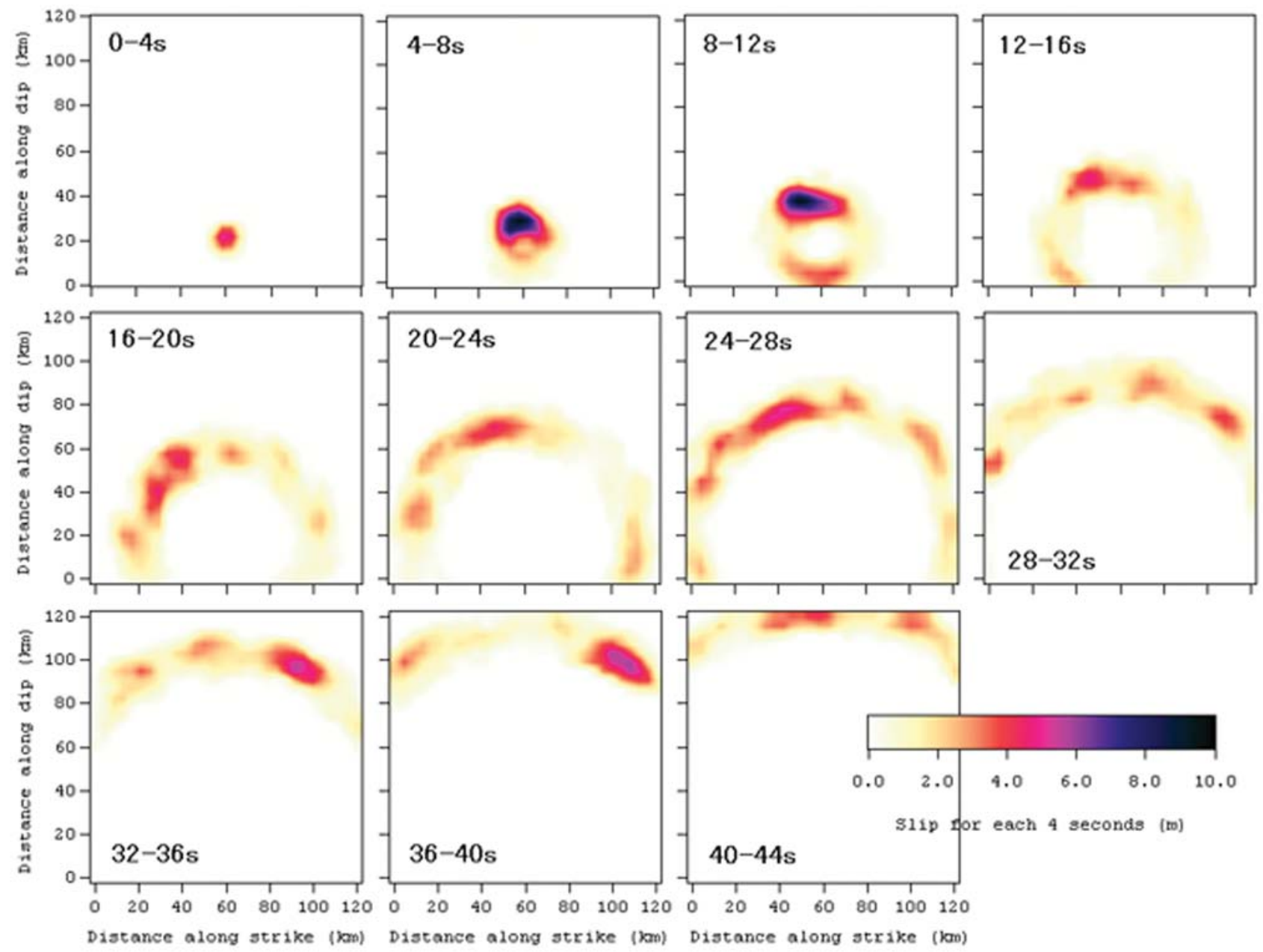

Figure 15. Slip for each $4 \mathrm{sec}$ of the 2003 Tokachi-oki earthquake obtained by the final inversion.

(2004) and the northern half of the asperity (b) by Honda et al. (2004).

Thus, the SMGAs identified in this study agree well with asperities identified from inverted results so far obtained using lower-frequency ground motions plus geodetic data and tsunamis. It implies that strong ground motions up to $1 \mathrm{~Hz}$ were generated from almost the same asperities producing lower-frequency ground motions. In terms of the complexity of slip models, although our analysis is focused on high frequencies, our slip model is at least as simple as conventional low-frequency slip models. Such results would be useful in constructing source models of future great subduction-zone earthquakes for strong-motion prediction.

The rupture velocity preferred in our analysis $(2.6 \mathrm{~km} / \mathrm{sec})$ is smaller than those used in the conventional low-frequency inversions, for example, $4.5 \mathrm{~km} / \mathrm{sec}$ suggested by Yagi (2004). This is probably because our analysis is focused on the main rupture that generated high frequencies following the rupture of SMGA 1, and thus, our value of rupture velocity is mainly controlled by the time lag between the rupture of SMGA 1 and that of SMGA 2. Kamae and Ka- wabe (2004), who are also focussed on high frequencies, used a relatively small rupture velocity $(2.8 \mathrm{~km} / \mathrm{sec})$, which is comparable to ours.

\section{Problems in Transverse Components}

Finally, the limitation of the present model associated with the applicability to the transverse component is discussed. Figure 18 shows comparisons of observed (gray traces) and synthetic (black traces) transverse ground velocities, band-pass filtered between 0.1 and $1 \mathrm{~Hz}$, at some stations. The synthetic velocities were computed from the final slip model (Fig. 13). At TKCH05, TKCH08, and KSRH09, transverse synthetic ground velocities agree well with the observed ones. At TKCH03, however, transverse ground velocity is underestimated. As mentioned earlier, the radiation coeffieients for $S H$ waves are much more sensitive to a small change in the rake angle than those for $S V$ waves in the areas where strong-motion sites are located (Fig. 8). Such a sensitivity may have caused the discrepancy found in the transverse components. 

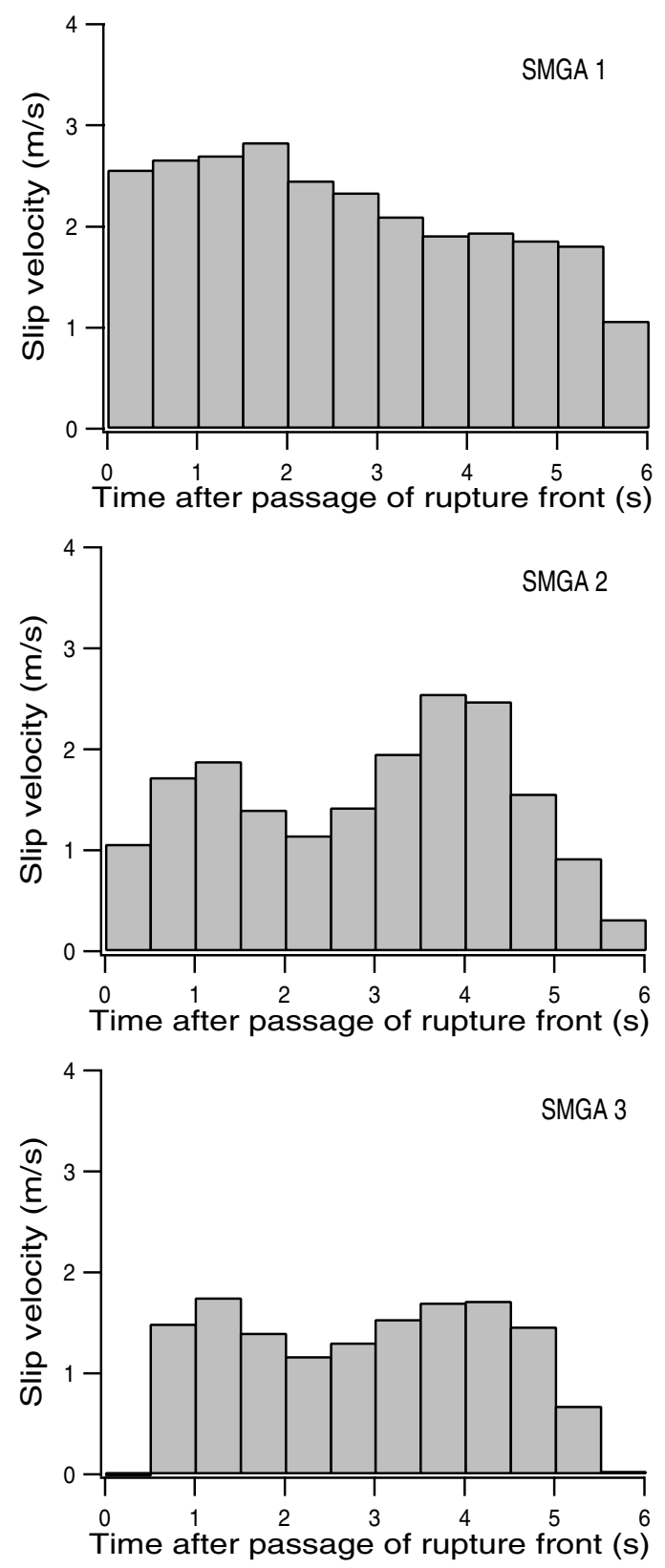

Figure 16. Representative slip velocity time functions for each SMGA. The time functions correspond to the element with the largest final slip in each SMGA. The slip velocity should be regarded as the averaged value over the time window used for the waveform inversion $(0.5 \mathrm{sec})$.

\section{Conclusions}

A waveform inversion was conducted for the 2003 Tokachi-oki, Japan, earthquake $\left(M_{\mathrm{J}}\right.$ 8.0) using empirical Green's functions to estimate SMGAs of the earthquake that generated high-frequency ground motions with frequencies up to $1 \mathrm{~Hz}$. We selected three aftershocks for use in the analysis, referring to the similarity of the group delay time between the mainshock and the aftershock records. Three

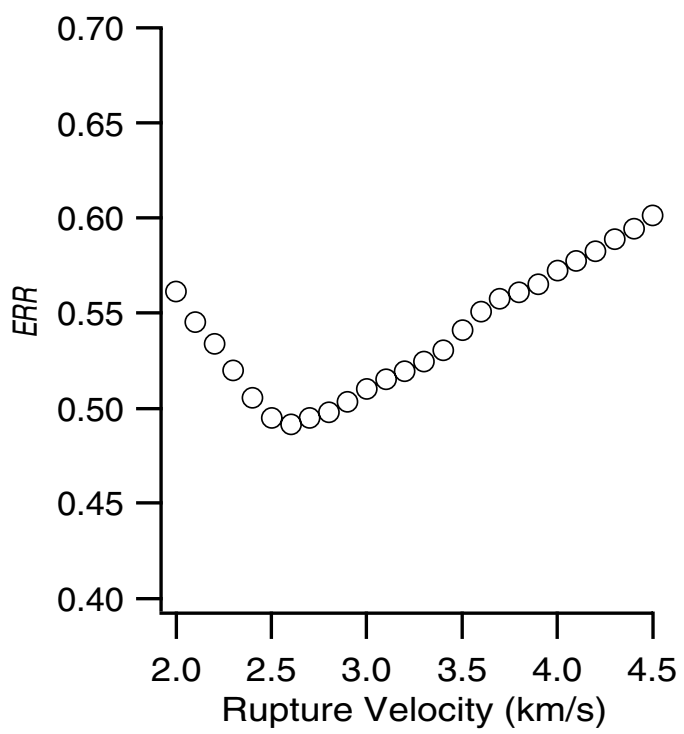

Figure 17. Relation between the rupture velocity and ERR in equation (2). ERR is minimized when we use a rupture velocity of $2.6 \mathrm{~km} / \mathrm{sec}$.

cases of inversions are conducted, namely, case 1 in which only one aftershock was used, case 2 in which two aftershocks were used, and case 3 in which three aftershocks were used. Case 3 yielded the best results. The resultant slip model has three SMGAs, each of which is close to the location of one of the aftershocks used as an empirical Green's function event. We found that careful selection of aftershocks is very effective for estimating ground motions from the mainshock, taking into account the similarity of the group delay time between the mainshock and the aftershock records. We confirmed that the ground motions with frequencies up to $1 \mathrm{~Hz}$ from a great subduction-zone earthquake can be modeled in a deterministic manner, once realistic Green's functions become available. Generally speaking, locations of the SMGAs identified in this study agree well with asperities identified from inverted results using lower-frequency (lower than $0.2 \mathrm{~Hz}$ ) ground motions plus geodetic data and tsunamis. It implies that strong ground motions up to $1 \mathrm{~Hz}$ were generated from the asperities producing lower-frequency ground motions. In terms of the complexity of slip models, although our analysis is focused on high frequencies, our slip model is at least as simple as conventional low-frequency slip models. Such results would be useful in constructing source models of future great subduction-zone earthquakes for strongmotion prediction.

\section{Acknowledgments}

We would like to express our gratitude to the National Research Institute for Earth Science and Disaster Prevention (NIED), Japan, for providing important strong-motion data from K-NET and KiK-net and the moment tensor catalog from F-net. We would also like to thank the Japan Meteorological Agency for providing source parameters for the 2003 Tokachi-oki 

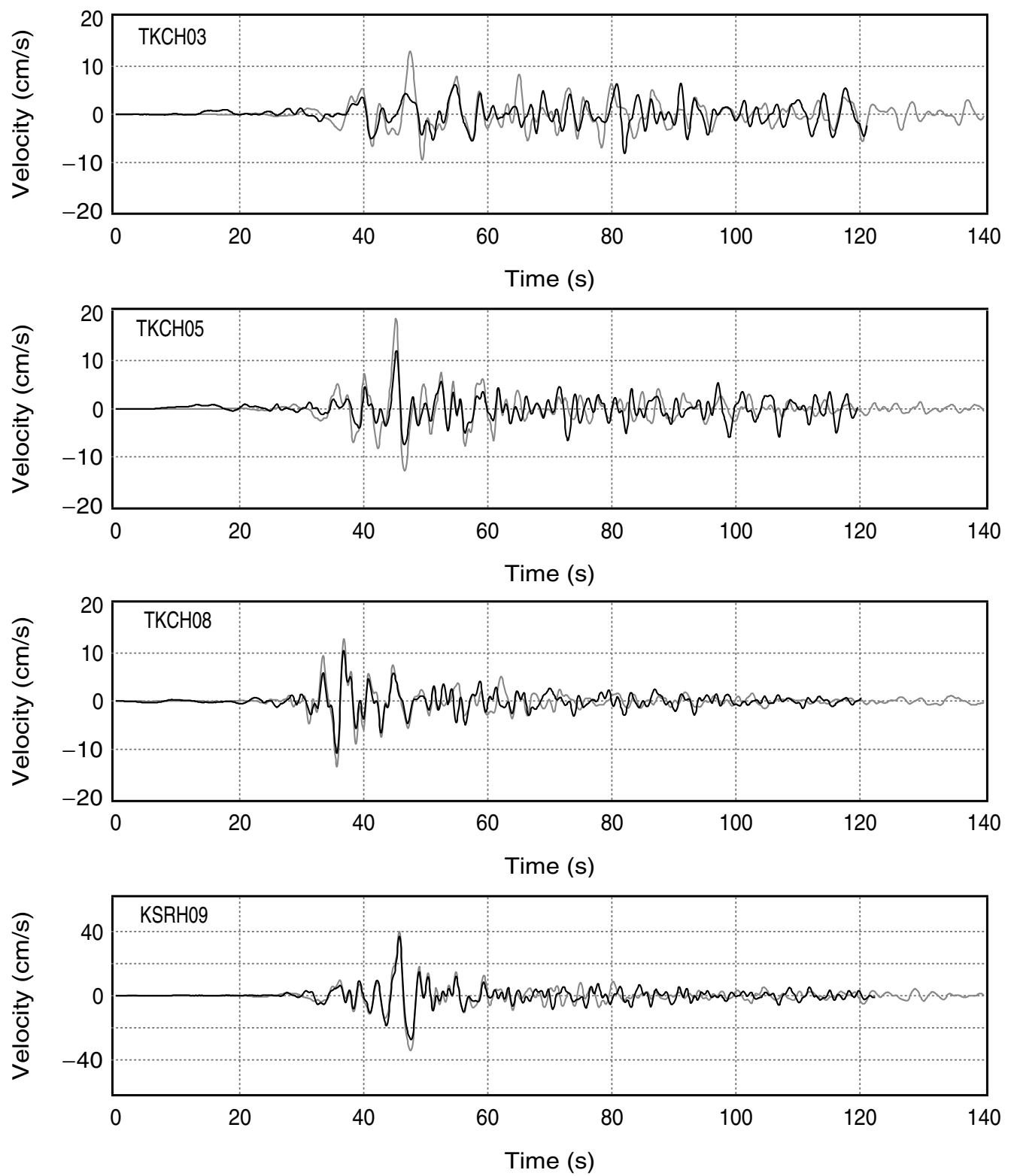

Figure 18. Synthetic transverse velocities (black traces) from the final slip-model (Fig. 13) are compared with the observed velocities (gray traces) at four stations. At TKCH03, the observed transverse velocity is characterized by a large-amplitude pulselike motion, which is not captured by the synthetic velocity.

mainshock and aftershocks. The manuscript was significantly improved by the comments from Hiroshi Kawase, Kyushu University, and two anonymous reviewers.

\section{References}

Aoi, S., K. Obara, S. Hori, K. Kasahara, and Y. Okada (2000). New strongmotion observation network: KiK-net, EOS 81, 329.

Beauval, C., P. Y. Bard, P. Maczo, and J. Kristek (2003). Quantification of frequency-dependent lengthening of seismic ground motion duration due to local geology: application to the Volvi Area (Greece), Bull. Seismol. Soc. Am. 93, 371-385.
Fukuyama, E., M. Ishida, S. Hori, S. Sekiguchi, and S. Watada (1996). Broadband seismic observation conducted under the FREESIA Project, Rep. Natl. Res. Inst. Earth Sci, Disaster Prev. 57, 23-31.

Hartzell, S. H. (1978). Earthquake aftershock as Green's functions, Geophys. Res. Lett. 5, 1-4.

Hartzell, S. H., and T. H. Heaton (1983). Inversion of strong ground motion and teleseismic waveform data for the fault rupture history of the 1979 Imperial Valley, California, earthquake, Bull. Seismol. Soc. Am. 73, $1553-1583$

Hatayama, K., S. Zama, H. Nishi, M. Yamada, Y. Hirokawa, and R. Inoue (2004). Long-period strong ground motion and damage to oil storage tanks due to the 2003 Tokachi-oki earthquake, J. Seism. Soc. Jpn. 57, 83-103 (in Japanese).

Hirata, K., Y. Tanioka, K. Satake, S. Yamaki, and E. L. Geist (2004). The tsunami source area of the 2003 Tokachi-oki earthquake estimated 
from tsunami travel times and its relationship to the 1952 Tokachi-oki earthquake, Earth Planet. Space 56, 367-372.

Honda, R., S. Aoi, N. Morikawa, H. Sekiguchi, K. Kunugi, and H. Fujiwara (2004). Ground motion and rupture process of the 2003 Tokachi-oki earthquake obtained from strong motion data of the K-NET and KiK-net, Earth Planet. Space 56, 317-322.

Ide, S., and M. Takeo (1996). The dynamic rupture process of the 1993 Kushiro-oki earthquake, J. Geophys. Res. 101, 5661-5675.

Irikura, K. (1983). Semi-empirical estimation of strong ground motions during large earthquakes, Bull. Disaster Prev. Res. Inst. 32, 63-104.

Kamae, K., and H. Kawabe (2004). Source model composed of asperities for the 2003 Tokachi-oki, Japan, earthquake $\left(\mathrm{M}_{\mathrm{JMA}}=8.0\right)$ estimated by the empirical Green's function method, Earth Planet. Space 56, 323-327.

Kinoshita, S. (1998). Kyoshin-net (K-NET), Seism. Res. Lett. 69, 309-332.

Koketsu, K., K. Hatayama, T. Furumura, Y. Ikegami, and S. Akiyama (2005). Damaging long-period ground motions from the 2003 $\mathrm{M}_{\mathrm{w}} 8.3$ Tokachi-oki, Japan, earthquake, Seism. Res. Lett. 76, 67-73.

Koketsu, K., K. Hikima, S. Miyazaki, and S. Ide (2004). Joint inversion of strong motion and geodetic data for the source rupture process of the 2003 Tokachi-oki, Hokkaido, earthquake, Earth Planet. Space 56, 329-334.

Lawson, C. L., and R. J. Hanson (1974). Solving Least Squares Problems, Prentice Hall, Englewood Cliffs, New Jersey.

Miyakoshi, K., T. Kagawa, H. Sekiguchi, T. Iwata, and K. Irikura (2000). Source characterization of inland earthquakes in Japan using source inversion results, in Proc. 12th World Conf. Earthquake Engineering, Aukland, New Zealand, 30 January-4 February: available on CD-ROM.

Nozu, A. (2005). Variable-slip rupture model for the 2004 Mid Niigata Prefecture (Niigata-ken Chuetsu) earthquake-waveform inversion with empirical Green's functions, Zisin 58, 329-343 (in Japanese with English abstract).

Obara, K. (2002). Hi-net: high sensitivity seismograph network, Japan, Lect. Note Earth Sci. 98, 79-87.

Sawada, S., H. Morikawa, K. Toki, and K. Yokoyama (1998). Identification of path and local site effects on phase spectrum of seismic motion, in Proc. 10th Japan Conf. Earthquake Engineering, Yokohama, Japan, 25-27 November, 915-920.

Tsuchida, H., E. Kurata, and K. Sudo (1969). Technical note no. 80, Strongmotion earthquake records on the 1968 Tokachi-oki earthquake and its aftershocks, Port and Harbour Research Institute (in Japanese).

Yagi, Y. (2004). Source rupture process of the 2003 Tokachi-oki earthquake determined by joint inversion of teleseismic body wave and strong ground motion data, Earth Planet. Space 56, 311-316.

Yamanaka, Y., and M. Kikuchi (2003). Source process of the recurrent Tokachi-oki earthquake on September 26, 2003, inferred from teleseismic body waves, Earth Planet. Space 55, e21-e24.

Geotechnical and Structural Engineering Department

Port and Airport Research Institute

3-1-1, Nagase

Yokosuka 239-0826, Japan

(A.N.)

Disaster Prevention Research Center

Aichi Institute of Technology

1247 Yachigusa

Yagusa, Toyota 470-0392, Japan

(K.I.)

Manuscript received 28 August 2006 